\title{
A Novel Intragenic Deletion in Ophn1 in A Boy with Developmental Delay, Strabismus and Cerebellar Hypoplasia
}

\author{
Luisa Ronzoni ${ }^{1}$, Lidia Pezzani ${ }^{2}$, Donatella Milani ${ }^{1 *}$, Pietro Chiurazzi ${ }^{3}$, Maria Grazia Pomponi ${ }^{3}$, Roberta Pietrobono ${ }^{3}$, \\ Maurizio Viri' ${ }^{4}$ and Susanna Esposito ${ }^{1}$ \\ ${ }^{1}$ Pediatric Highly Intensive Care Unit, Department of Pathophysiology and Transplantation, Università degli Studi di Milano, Fondazione IRCCS \\ Ca' Granda Ospedale Maggiore Policlinico, Milan, Italy \\ ${ }^{2}$ Department of Pathophysiology and Transplantation, Università degli Studi di Milano, Pathology Unit, Fondazione IRCCS Ca' Granda Ospedale \\ Maggiore Policlinico, Milan, Italy. \\ ${ }^{3}$ Institute of Medical Genetics, Catholic University Faculty of Medicine, Rome, Italy \\ ${ }^{4}$ Pediatric Neurology Unit and Epilepsy Center, Department of Neuroscience, "Fatebenefratelli e Oftalmico" Hospital, Milan, Italy
}

\section{Abstract}

Background: X-linked intellectual disability (XLID) is a notably heterogeneous condition and often poses a diagnostic challenge; it is more common in males than females, indicating a role of defects on the $\mathrm{X}$ chromosome. The oligophrenin-1 (OPHN1) gene on Xq12 is one of the genes responsible for a syndromic form of XLID characterized by specific brain anomalies and distinctive facial features.

Methods: We report a boy with developmental delay, convergent strabismus, severe hypermetropia, seizures, facial dysmorphisms and cerebellar vermis hypoplasia.

Results: A novel intragenic deletion in the OPHN1 gene was found.

Conclusion: The report underlines the clinical and neuroradiological features associated with OPHN1 mutations, confirming that alterations in this gene are responsible for a significant proportion of patients with syndromic XLID with brain anomalies. Thus, we suggest that brain MRI examinations should be performed on all individuals with XLID with hypotonia, motor delays and severe strabismus.

\section{Publication History:}

Received: March 31, 2015

Accepted: May 12, 2015

Published: May 14, 2015

\section{Keywords:}

Oligophrenin-1, X-linked Intellectual disability, Cerebellar hypoplasia, Strabismus, Seizures, OPHN1, Deep-set eyes

\section{Introduction}

Intellectual disability (ID), usually defined as an overall IQ of $<70$, affects $\sim 3 \%$ of the human population and can be classified into syndromic and non-syndromic subtypes based on the presence or absence of dysmorphic and somatic features [1,2]. ID is more common in males than females, indicating a role of defects on the $\mathrm{X}$ chromosome; mutations in X-linked genes actually contribute to 10 $15 \%$ of ID cases in males $[3,4]$.

In recent years, many new genes responsible for X-linked inherited ID have been identified by taking advantage of powerful positionalcloning strategies [5].

The oligophrenin-1 (OPHN1) gene on Xq12 is one of the genes responsible for a syndromic form of X-linked ID (S-XLID). The distinctive phenotype comprises intellectual disability, a specific facial appearance, strabismus, myoclonic-astatic epilepsy, ataxia, hypogenitalism and specific brain anomalies with cerebellar hypoplasia [6-11]. Carrier females have been reported to be mildly affected with subtle facial dysmorphic features and mild cognitive delays and may or may not have abnormal brain imaging findings $[9,12]$.

To date, a total of 26 mutations involving the OPHN1 gene have been reported (only 19 of which are publicly available), consisting of missense/nonsense and splicing mutations, small and gross insertions and deletions and two complex rearrangements.

Here we report a family with XLID due to a new intragenic deletion in the OPHN1 gene.

\section{Case Presentation}

The patient was the first child born to a healthy and nonconsanguineous couple. During pregnancy, cerebellar vermis hypoplasia was detected by a routine 18-week ultrasound examination and confirmed by fetal MRI, which also detected enlargement of the lateral ventricles. The boy was born at term by spontaneous delivery; his birth weight, length, and occipitofrontal circumference (OFC) were $3,320 \mathrm{~g}$ (25-50th percentile), $49 \mathrm{~cm}$ (10-25 $5^{\text {th }}$ percentile), and 35 $\mathrm{cm}\left(25-50^{\text {th }}\right.$ percentile $)$, respectively. His Apgar scores were 9 at the $1 \mathrm{st}$ minute and 10 at the $5^{\text {th }}$ minute.

An ophthalmological evaluation at 8 months showed marked convergent strabismus and severe hypermetropia. At the age of 9 months, he developed generalized myoclonic seizures occurring up to 10 attacks per day. Interictal video-electroencephalography (VEEG) during awake showed spike wave abnormalities in right occipital temporal regions, while during myoclonic jerk VEEG showed generalized irregular spike wave complex. Therefore, he was started on valproate, which controlled the seizures. At 11 months, a brain MRI confirmed the presence of cerebellar vermis hypoplasia, cisterna magna enlargement, and dilatation of the lateral ventricles, and it also showed squared frontal horns and a thin corpus callosum. A psychomotor delay was noted during the first year of life, as he was able to sit at 10 months; walking with an ataxic gate was achieved by 30 months of age, and he showed a moderate speech impairment. Moreover, a neurological examination revealed generalized hypotonia and fine and gross motor skill impairment, and an IQ assessment showed a severe cognitive delay. A physical examination at 31 months

"Corresponding Author: Donatella Milani, Pediatric Highly Intensive Care Unit, Department of Pathophysiology and Transplantation, Università degli Studi di Milano, Fondazione IRCCS Ca' Granda Ospedale Maggiore Policlinico, Via Commenda 9, 20122 Milano, Italy, Tel.: +39-02-55032412, Fax: +39-0250320206; E-mail: donatella.milani@policlinico.mi.it

Citation: Ronzoni L, Pezzani L, Milani D, Chiurazzi P, Pomponi MG, et al. (2015) A Novel Intragenic Deletion in Ophn1 in A Boy with Developmental Delay, Strabismus and Cerebellar Hypoplasia. Int J Pediatr Neonat Care 1: 104. doi: http://dx.doi.org/10.15344/2455-2364/2015/104

Copyright: (C) 2015 Ronzoni et al. This is an open-access article distributed under the terms of the Creative Commons Attribution License, which permits unrestricted use, distribution, and reproduction in any medium, provided the original author and source are credited. 
Citation: Ronzoni L, Pezzani L, Milani D, Chiurazzi P, Pomponi MG, et al. (2015) A Novel Intragenic Deletion in Ophn1 in A Boy with Developmental Delay, Strabismus and Cerebellar Hypoplasia. Int J Pediatr Neonat Care 1: 104. doi: http://dx.doi.org/10.15344/2455-2364/2015/104

Page 2 of 3

of age showed an OFC of $48 \mathrm{~cm}$ (10th percentile), height of $87 \mathrm{~cm}$ (10-25 $5^{\text {th }}$ percentile) and weight of $11.450 \mathrm{~kg}\left(3-10^{\text {th }}\right.$ percentile); he also exhibited facial dysmorphisms with a roundish shape of the face, sparse eyebrows, deep-set eyes, a short philtrum and mild retrognathia with a horizontal notch. An abdominal ultrasound showed no alterations, and genital anomalies were not detected. Conventional karyotyping and an array-CGH were normal.

\section{Methods}

To check for mutations in the OPHN1 gene sequence, we amplified the coding exons (2-24) with 24 primer pairs designed using Primer Express v1.5 software. PCR was performed in a $20 \mu \mathrm{l}$ reaction volume with $50 \mathrm{ng}$ of genomic DNA, and Taq, Buffer, $\mathrm{MgCl}_{2}$, and dNTPs were supplied by Promega Master mix (2x). PCR reactions were performed for 35 cycles. Each cycle consisted of $1 \mathrm{~min}$ of denaturation at $95^{\circ} \mathrm{C}$, $1 \mathrm{~min}$ of annealing at an appropriate temperature $\left(55-60^{\circ} \mathrm{C}\right)$ and 1 min of elongation at $72^{\circ} \mathrm{C}$. The PCR products were examined on a $2 \%$ agarose gel, and after ExoSAP purification, they were sequenced using the Applied Biosystem BigDye Terminator v3.1 Cycle Sequencing Kit and run on the ABI PRISM 3500 Genetic Analyzer (Applied Biosystems). Sequence analysis was performed with SeqScape 2.7 software.

\section{Results}

Because the proband did not amplify exons 13 and 14, we attempted to amplify his genomic DNA using primer 12-Forward and 15 -Reverse, which should produce a $4.5 \mathrm{~kb}$ fragment. Instead, using TaKaRa LA Taq with a GC buffer and special PCR conditions (30 cycles with $10 \mathrm{sec}$ of denaturation at $98^{\circ} \mathrm{C}$ and $15 \mathrm{~min}$ of annealingelongation at $68^{\circ} \mathrm{C}$ ), we obtained a $1.5 \mathrm{~kb}$ fragment. Sequencing of this fragment allowed us to determine the deletion breakpoints that removed nucleotides 242 351-345 371 from the NG_008960.1 genomic sequence. The 5 ' breakpoint was located in intron 12 , and the 3 ' breakpoint was located in intron 14 . The same deletion was found in the proband's mother.

At the mRNA level, the deletion resulted in the removal of nucleotides 1105-1201 (corresponding to exons 13 and 14 on the NM_002547.2 cDNA sequence), resulting in a frameshift mutation that inserts a stop codon 21 amino acids after proline 368 (the last normally translated residue).

\section{Discussion}

Oligophrenin-1 (OPHN1) is one of at least seven genes located on the $\mathrm{X}$ chromosome that take part in the Rho GTPase-dependent signaling pathways involved in several cellular functions including neuronal cell migration and synaptic morphogenesis [13,14]. OPHN1 encodes for a 91-kd protein that is highly expressed in axons, dendrites and spines throughout the brain; its expression is enriched in the hippocampus, olfactory bulb and Purkinje cell layer of the cerebellum. Dysfunction of the oligophrenin protein might result in the constitutive activation of the Rho protein family members, affecting neuronal morphogenesis and synapse maturation $[13,15,16]$. Rho-pathway dysfunction and abnormal kinetic efficiency of endocytosis due to OPHN1 protein defects are thought to be important contributory factors to a specific form of XLID associated with cerebellar hypoplasia with vermian dysplasia [8,10,17-19].

In this report, we establish the molecular diagnosis of a boy with a clinical picture comprising psychomotor delays, strabismus, hypermetropia, epilepsy, ataxia and distinctive neuroradiological findings. The phenotype was suggestive of XLID; the presence of cerebellar hypoplasia and easily recognizable facial dysmorphic features suggested OPHN1-related XLID.

The most striking hallmark shared by OPHN1 patients, aside from moderate to severe cognitive impairment, is the presence of MRI abnormalities: the posterior fossa is involved in all cases; cerebellar hypoplasia is predominant at the level of the lower vermis; the involvement of cerebellar hemispheres is variable and ranges from an enlarged cisterna magna to retrocerebellar cysts; disorganization of the anterior vermis has also been reported as well as hippocampal alterations $[8,10,20]$.

The most characteristic facial findings associated with OPHN1 syndrome include hypotelorism, deep-set eyes, prominent supraorbital ridges, a short philtrum, thin upper lip and prognathism $[6,9,10]$.

Strabismus is another useful clinical sign that suggests a diagnosis of OPHN1 syndrome. All OPHN1 patients share marked strabismus, which is more pronounced than the ocular features frequently described in other ID syndromes $[9,10,21]$. The critical role of the cerebellum in oculomotor coordination might contribute to the ocular impairment [22].

Other features shown by our proband, such as early-onset myoclonic and motor focal seizures and overt ataxia, have been reported in some patients $[6,8,10]$; partial motor seizures, observed in $50 \%$ of mutated families, could be related to the supratentorial involvement described in OPHN1 patients $[8,10]$. Obvious ataxia is rarely observed in spite of severe cerebellar hypoplasia; this has been suggested to be consistent with a prominent posterior vermian dysgenesis with a less affected rostral vermis $[10,11]$. A high degree of intrafamilial and interfamilial variability in the severity of the clinical and neurologic manifestations of the syndrome ranging from moderate ID with mild motor incoordination to severe cognitive impairment with complete loss of autonomy has been described [23].

Our report also gives an insight into the presentation of carrier females that have been reported to be mildly affected with subtle facial dysmorphic features and mild cognitive delay with or without abnormal findings on brain imaging [9,12, 24-26]. The mother of our patient has actually been detected as a carrier of the same deletion that affects her son; however, she shows normal intelligence and only subtle dysmorphic features, including a long face with deep-set eyes. This phenomenon could be attributed to skewed X-inactivation as previously described in various X-linked disorders including XLID $[27,28]$.

The majority of OPHN1 mutations identified to date (nonsense, missense and splicing mutations; small deletions and insertions) result in oligophrenin-1 loss of function; splicing mutations that determine the production of a mutant protein have also been described [26], as well as two complex rearrangements involving the OPHN1 gene $[12,24]$.

The intragenic deletion found in our family has not yet been reported in the literature. This deletion removes exons 13 and 14 from the mRNA resulting in a frameshift mutation that inserts a premature stop codon. We cannot rule out that Nonsense-Mediated Decay results in the absence of OPHN1 mRNA in the proband, but if the transcript should be translated, it would result in the production of a truncated 
Citation: Ronzoni L, Pezzani L, Milani D, Chiurazzi P, Pomponi MG, et al. (2015) A Novel Intragenic Deletion in Ophn1 in A Boy with Developmental Delay, Strabismus and Cerebellar Hypoplasia. Int J Pediatr Neonat Care 1: 104. doi: http://dx.doi.org/10.15344/2455-2364/2015/104

Page 3 of 3

protein with only the N-terminal BAR and pleckstrin-homology $(\mathrm{PH})$ domains and lacking the entire Rho GTPase Activation Protein (GAP) domain and the following 240 amino acid-long C-terminus of the OPHN1 protein.

\section{Conclusion}

The diagnostic approach to patients with suspected X-linked intellectual disability (XLID) is regarded as one of the most difficult tasks for clinicians. The current study confirms that OPHN1 gene alterations are responsible for a significant proportion of male patients with syndromic XLID associated with cerebellar hypoplasia. Based on this evidence, we suggest that an MRI examination of the brain should be performed on all individuals with XLID with hypotonia, motor delay and severe strabismus. Moreover, the identification of heterozygous females, although more difficult due to their subtle facial phenotype and possible lack of brain malformations, is an important challenge for genetic counseling.

\section{Competing Interests}

The authors have no competing interests to declare.

\section{Author Contributions}

LR, LP and DM drafted the manuscript. PC, MGP and RP performed the analysis and interpretation of data. MV is the neurologist who cared for the child and performed the MRI and EEG examinations. SE revised the manuscript and made substantial scientific contributions. All authors have read and approved the final version of the manuscript.

\section{Acknowledgments}

The authors thank the patient and his parents for allowing us to publish this case report.

\section{References}

1. Leonard $\mathrm{H}$, Wen $\mathrm{X}$ (2002) The epidemiology of mental retardation: challenges and opportunities in the new millennium. Ment Retard Dev Disabil Res Rev 8: 117-134

2. Stevenson RE, Schwartz CE, Schroer RJ (2000) X-linked mental retardation. New York: Oxford University Press.

3. de Brouwer AP, Yntema HG, Kleefstra T, Lugtenberg D, Oudakker AR, et al. (2007) Mutation frequencies of X-linked mental retardation genes in families from the EuroMRX consortium. Hum Mutat 28: 207-208.

4. Raymond FL (2006) X linked mental retardation: a clinical guide. J Med Genet 43: 193-200.

5. Philips AK, Siren A, Avela K, Somer M, Peippo M, et al. (2014) X-exome sequencing in Finnish families with Intellectual Disability - four nove mutations and two novel syndromic phenotypes. Orphanet J Rare Dis 9: 49-62.

6. Bergmann C, Zerres K, Senderek J, Rudnik-Schoneborn S, Eggermann T, et al. (2003) Oligophrenin 1 (OPHN1) gene mutation causes syndromic $\mathrm{X}$-linked mental retardation with epilepsy, rostral ventricular enlargement and cerebellar hypoplasia. Brain 126: 1537-1544.

7. Philip N, Chabrol B, Lossi AM, Cardoso C, Guerrini R, et al. (2003) Mutations in the oligophrenin-1 gene (OPHN1) cause $X$ linked congenital cerebellar hypoplasia. J Med Genet 40: 441-446.

8. Chabrol B, Girard N, N'Guyen K, Gérard A, Carlier M, et al. (2005) Delineation of the clinical phenotype associated with OPHN1 mutations based on the clinical and neuropsychological evaluation of three families. Am J Med Genet A 138: 314-317.
9. Al-Owain M, Kaya N, Al-Zaidan H, Al-Hashmi N, Al-Bakheet A, et al. (2011) Novel intragenic deletion in OPHN1 in a family causing XLMR with cerebellar hypoplasia and distinctive facial appearance. Clin Genet 79: 363-370.

10. des Portes V, Boddaert N, Sacco S, Briault S, Maincent K, et al. (2004) Specific clinical and brain MRI features in mentally retarded patients with mutations in the Oligophrenin-1 gene. Am J Med Genet A 124A: 364-371.

11. Higgins JJ, Topaloglu $\mathrm{H}$ (2005) X-linked oligophrenic vermian dysgenesis: syndromic vs non-syndromic X-linked mental retardation? Neurology 65 : 1346-1347.

12. Menten B, Buysse K, Vermeulen S, Meersschaut V, Vandesompele J, et al. (2007) Report of a female patient with mental retardation and tall stature due to a chromosomal rearrangement disrupting the OPHN1 gene on Xq12. Eur J Med Genet 50: 446-454.

13. Barresi S, Tomaselli S, Athanasiadis A, Galeano F, Locatelli F, et al. (2014) Oligophrenin-1 (OPHN1), a gene involved in X-linked intellectual disability, undergoes RNA editing and alternative splicing during human brain development. PLoS One 9: e91351.

14. Billuart P, Bienvenu T, Ronce N, des Portes V, Vinet MC, et al. (1998) Oligophrenin-1 encodes a rhoGAP protein involved in X-linked mental retardation. Nature 392: 923-926.

15. Fauchereau F, Herbrand U, Chafey P, Eberth A, Koulakoff A, et al. (2003) The RhoGAP activity of OPHN1, a new F-actin-binding protein, is negatively controlled by its amino-terminal domain. Mol Cell Neurosci 23: 574-586.

16. Govek EE, Newey SE, Akerman CJ, Cross JR, Van der Veken L, et al. (2004) The X-linked mental retardation protein oligophrenin-1 is required for dendritic spine morphogenesis. Nat Neurosci 7: 364-372.

17. Nakano-Kobayashi A, Kasri NN, Newey SE, Van Aelst L (2009) The Rho-linked mental retardation protein OPHN1 controls synaptic vesicle endocytosis via endophilin A1. Curr Biol 19: 1133-1139.

18. Nadif Kasri N, Nakano-Kobayashi A, Malinow R, Li B, Van Aelst L (2009) The Rho-linked mental retardation protein oligophrenin-1 controls synapse maturation and plasticity by stabilizing AMPA receptors. Genes Dev 23 : 1289-1302.

19. Benarroch EE (2007) Rho GTPases: role in dendrite and axonal growth, mental retardation, and axonal regeneration. Neurology 68: 1315-1318.

20. Santos-Reboucas CB, Belet S, Guedes de Almeida L, Ribeiro MG, MedinaAcosta $E$, et al. (2014) A novel in-frame deletion affecting the BAR domain of OPHN1 in a family with intellectual disability and hippocampal alterations. Eur J Hum Genet 22: 644-651.

21. Hagerman RJ, Hills J, Scharfenaker S, Lewis H (1999) Fragile X syndrome and selective mutism. Am J Med Genet 83: 313-317.

22. Nolte J (2002) Cerebellum In: Nolte John, ed The human brain, an introduction to its functional anatomy. 5th edition, St. Louis, MI: Mosby, Inc.; Harcourt Health Sciences Company 486-510.

23. Zanni G, Saillour $Y$, Nagara M, Billuart $P$, Castelnau L, et al. (2005) Oligophrenin 1 mutations frequently cause $X$-linked mental retardation with cerebellar hypoplasia. Neurology 65: 1364-1369.

24. Bienvenu T, Der-Sarkissian H, Billuart P, Tissot M, Des Portes V, et al. (1997) Mapping of the X-breakpoint involved in a balanced X;12 translocation in a female with mild mental retardation. Eur J Hum Genet 5: 105-109.

25. Tentler D, Gustavsson P, Leisti J, Schueler M, Chelly J, et al. (1999) Deletion including the oligophrenin-1 gene associated with enlarged cerebral ventricles, cerebellar hypoplasia, seizures and ataxia. Eur J Hum Genet 7: 541-548.

26. Pirozzi F, Di Raimo FR, Zanni G, Bertini E, Billuart P, et al. (2011) Insertion of 16 amino acids in the BAR domain of the oligophrenin 1 protein causes mental retardation and cerebellar hypoplasia in an Italian family. Hum Mutat 32: E2294-2307.

27. Amir RE, Zoghbi HY (2000) Rett syndrome: methyl-CpG-binding protein 2 mutations and phenotype-genotype correlations. Am J Med Genet 97 : 147-152.

28. Shastry BS (2000) Recent progress in the genetics of incontinentia pigmenti (Bloch-Sulzberger syndrome). J Hum Genet 45: 323-326. 